\title{
Isolation, identification, and technological characterization of wild leuconostocs and lactococci for traditional Raib type milk fermentation
}

\author{
Nahida Bendimerad • Mebrouk Kihal • \\ Françoise Berthier
}

Received: 15 July 2011 / Revised: 24 February 2012 / Accepted: 23 March 2012 /

Published online: 26 April 2012

(C) INRA and Springer-Verlag, France 2012

\begin{abstract}
Raib (Rayeb) is a spontaneously fermented milk primarily acidified and flavored by strains of lactococci and leuconostocs. Raib and its by-products are traditionally consumed in many Mediterranean and sub-Saharan countries. Dedicated ready-to-use starter strains are currently missing. The aim of this study was to isolate and characterize wild strains of lactococci and leuconostocs that could be used to produce these dairy products while preserving their traditional characteristics. Dominant lactic acid cocci were isolated on M17 and MRS-vancomycin plates from Algerian cow's, ewe's, goat's, mare's, and camel's milks, either raw and/or fermented under laboratory conditions. The DNA of the isolates was fingerprinted by Rep-PCR. Strain identification was performed by Rep-PCR combined with specific PCR for genus Enterococcus and subspecies lactis/hordniae and cremoris of Lactococcus lactis. Isolates were characterized for three phenotypes essential for Raib manufacture: (a) high acidifying activity over the normal associated temperature range, (b) presence of protease, and (c) ability to metabolize citrate. Eighty-four isolates were characterized including four different strains of lactococci and four different strains of leuconostocs. Vancomycin-resistant enterococci were often coisolated. One strain of Leuconostoc mesenteroides exhibited an atypical genotype compared to the subspecies-type strains and to other wild Leuconostoc strains. Two protease-positive strains of Lactococcus lactis subsp. lactis biovar diacetylactis isolated from camel's fermented milks and the
\end{abstract}

N. Bendimerad
LAMAABE, Biology Department, University Abou Bekr Belkaid, Tlemcen, Algeria

M. Kihal

Laboratory of Applied Microbiology, University Es-Senia, Oran, Algeria

F. Berthier $(\triangle)$

INRA, UR342 Dairy Technology and Analysis, 39800 Poligny, France

e-mail: francoise.berthier@poligny.inra.fr 
strain Leuconostoc mesenteroides subsp. mesenteroides isolated from mare's fermented milks had high acidifying potential in milk. These three strains were considered as suitable candidates as acidifying starters to preserve the typical sensory characteristics of traditional Raib while improving its safety and shelf life.

\section{传统Raib型发酵乳中天然明串珠菌和乳球菌的分离、鉴定以及工艺特性}

摘要: Raib(Rayeb)是由乳球菌和明串珠菌发酵产酸进而酸化和产生风味的一种自然发酵乳。 Raib以及其副产品是许多地中海和撒哈拉以南非洲国家的传统食品。当前尚未有用于发酵 Raib的专门发酵剂。本研究目的是分离和鉴定可用于Raib及其副产品的生产, 并能保持自身 传统特性的天然乳球菌和明串珠菌菌株。在实验室中, 采用M17和MRS (含万古霉素) 培养基, 从新鲜阿尔及利亚牛乳、绵羊乳、山羊乳、马乳、骆驼乳等原料乳或者其发酵乳中, 分离了 优势乳酸球菌。提取这些菌株的DNA, 并且采用Rep-PCR技术对上述菌株指纹图谱分析。采 用Rep-PCR技术结合Enterococcus属特异性引物、lactis/hordniae 和cremoris of Lactococcus lactis. 亚属特异性引物, 对菌株进行鉴定。分离获得菌株的三个与Raib生产相关的特性被确 定, 其中包括a)在正常的相关温度范围内体现的高酸化能力; b) 蛋白酶活性;c)柠檬酸代谢能 力。 84 株菌被定性, 其中包括 4 株乳球菌和 4 株明串珠菌。具有抗万古霉素的肠球菌, 常常被 共分离。一株Leuconostoc mesenteroides菌与亚种模式菌株以及其他天然明串珠菌相比, 显示 了非典型的表型特征。两株分离自骆驼发酵乳, 并具有蛋白酶活性的Lactococcus lactis subsp. lactis biovar diacetylactis 和分离自马发酵乳的Leuconostoc mesenteroides subsp. mesenteroides 在乳中显示高的酸化潜力。以上三株菌适合用作酸化发酵剂, 它们既可保留传统Raib的传统 的感官特性, 同时可以改善Raib的安全性和延长货架期。

Keywords Leuconostocs $\cdot$ Lactococci $\cdot$ Enterococci $\cdot$ Raib type milk fermentation $\cdot$ Rep-PCR

关键词 明串珠菌·乳球菌·肠球菌 $\cdot R a i b$ 型发酵乳 $\cdot R e p-P C R$

\section{Introduction}

There is a need to select novel microbial strains to improve safety of existing traditional fermented dairy products without altering their unique sensory, nutritional, and health-related characteristics; hitherto, strains have mostly been selected for products that have other sensory, nutritional, and health-related characteristics and are manufactured from cow's milk. The selection of strains from dairy ecosystems other than cow's milk and cheeses provides an opportunity to obtain strains which possess unique phenotypes (Drici et al. 2010) and may be useful for new dairy applications as well as traditional ones (Prashant et al. 2009).

Ready-to-use starters dedicated to the manufacture of traditional Raib and its byproducts are not currently available. The selection of novel strains is crucial to design such starters.

Raib and its by-products are traditional dairy products, still widely produced and consumed in many Mediterranean and sub-Saharan countries (Abou-Donia 2008; Benkerroum and Tamime 2004; Koussou et al. 2007). Raib is consumed directly after fermentation or is skimmed before use. When Raib is churned, Lben is obtained from the nonbutter fraction and Smen from the butter fraction. Jben is a soft white cheese obtained by molding, draining, and salting. The characteristics of Raib and its byproducts are broad ranging as they are largely still produced without standardized 
procedures. Until recently, they were mostly homemade in rural areas where they make a major contribution to people's diets as well as to the rural economy by promoting local production. Their consumption is increasing in some cities, but has been decreasing among the more prosperous population groups, who have replaced them with industrial-type yoghurts (Khaldi et al. 2006; Koussou et al. 2007). It has been estimated that $30 \%$ of Algerian milk output in the 1990 s was used to make these products, which were either consumed on-farm or marketed through informal channels (Bencharif 2001).

Traditionally, Raib results from the spontaneous fermentation of full-cream raw cow's, goat's, camel's, or ewe's milks. Cow's milk is also sometimes supplemented with goat's, ewe's, or camel's milk. Fermentation takes place at ambient temperature for 24 to $72 \mathrm{~h}$ depending on the temperature. Lactococcus lactis and Leuconostoc mesenteroides are generally cited as the main lactic acid bacteria (LAB) responsible for its acidification, texture, and aromatization (Benkerroum and Tamime 2004). In that respect, the LAB involved are similar to those used for cultured buttermilk made from cow's milk in developed countries (Vedamuthu 1994). Yeasts are also cited as secondary aroma contributors (Tantaoui-Elaraki and El Marrakchi 1987). All this gives traditional Raib and its by-products specific physicochemical compositions and organoleptic characteristics.

Currently, manufacturing practices are changing for various reasons such as to facilitate large-scale production, production in urban areas, availability of ready-to-use starters and rennet, and hygiene constraints. This results in modification of some essential characteristics such as acidity, levels of solids and volatile compounds, and rheological profiles (Guizani et al. 2001; Samet-Bali et al. 2010). The lactococci that predominated in traditional Laban and Jben have been replaced by thermophilic lactobacilli in their commercial counterparts (Benkerroum and Tamime 2004; Guizani et al. 2001). Practices for industrial Laban manufacturing are actually similar to those for conventional yoghurt in Lebanon (Chammas et al. 2006).

The consumption of ripened cream butter has declined in developed countries and with it, research on dedicated Leuconostoc strains. Many successful butter cultures containing good aroma-producing leuconostocs have also been lost because of neglect (Vedamuthu 1994). However, for flavor intensification without an objectionable green flavor defect or excessive gas, leuconostocs should be used in preference to citrate-fermenting lactococci in ripened cream butter made from cow's milk (Vedamuthu 1994). In milk, leuconostocs function only in association with lactococci, which initiate their growth (Vedamuthu 1994).

All previous studies of Raib and its by-products have described LAB isolated from ready-made products or from raw milks. With the exception of one recent study (Ouadghiri et al. 2009), LAB have previously been identified by unreliable phenotypic methods. The present study sets out to isolate wild strains of leuconostocs and lactococci that are well adapted to the different environments in which they are likely to grow. Strains of leuconostocs and lactococci were isolated from raw milks and/or spontaneously fermented raw milks of cow, ewe, mare, goat, and camel under laboratory conditions. They were identified by reliable and accurate genotypic methods, i.e., species-specific PCR when available (Wolfgang 2007) and Rep-PCR (Gevers et al. 2001), and were characterized for their potential as acidifiers and flavoring agents of Raib. 


\section{Materials and methods}

\subsection{Milk samples}

Milks were sampled in spring. To avoid isolating any commercial strains, milks were collected in sterile flasks directly at milking or from the milk can. They were kept at $4{ }^{\circ} \mathrm{C}$ until use; all were used within $24 \mathrm{~h}$. To ensure variability among the isolates, samples were taken from 40 different farms.

\subsection{Strain isolation}

MRS-vancomycin (vancomycin at $20 \mathrm{mg} . \mathrm{L}^{-1}$ ) (Mathot et al. 1994) and M17 (Terzaghi and Sandine 1975) were used to isolate leuconostocs and lactococci, respectively. Strains were isolated directly from raw milks or after spontaneous fermentation of raw milks at $30{ }^{\circ} \mathrm{C}$ for $48 \mathrm{~h}$ ( $96 \mathrm{~h}$ for camel's milks), mimicking traditional fermentation. The aim was to obtain strains that are active during the first production stages and, therefore, common to Raib and its by-products. Aliquots $(0.1 \mathrm{~mL})$ of raw or fermented milks were cultivated in MRS-vancomycin broth; then, aliquots from cultures that produced gas in Durham tubes were streaked on MRS-vancomycin plates. Aliquots $(0.1 \mathrm{~mL})$ of raw or fermented milks were also cultivated in M17 broth; then, aliquots from cultures that did not produce gas in Durham tubes were streaked on M17 plates. The cultures were incubated aerobically at $30^{\circ} \mathrm{C}$ for $24 \mathrm{~h}$.

Isolated colonies were picked off plates and purified by two successive streakings on MRS-vancomycin or M17 plates. By taking only a few isolates from each sample, redundancy among isolates was avoided, and it can be assumed that only dominant strains were isolated from the milks, with strains well adapted to the different milks that are likely to be fermented. The isolates were stored at $-20{ }^{\circ} \mathrm{C}$ in sterile milk supplemented with glycerol (15\%), glucose $(0.5 \%)$, and yeast extract $(0.25 \%)$.

\subsection{Type strains}

Type strains (see Fig. 1) were obtained from ATCC, American Type Culture Collection (Rockville, MD, USA); CIP, Collection of the Institute Pasteur (Paris, France); and CNRZ, Collection of the Centre National de la Recherche Zootechnique (INRA, Jouy-en-Josas, France) distributed now by CIRM-BIA (INRA, Rennes, France).

\subsection{DNA extraction}

Each purified isolate and each type strain was streaked on an appropriate agar medium. Total DNA was extracted from one colony by the rapid cold shock method of Gaya et al. (1999).

\subsection{Rep-PCR}

Rep-PCR was performed as described by Berthier et al. (2001), except that the gel image was captured with a CCD camera, and primer (GTG) 5 (5P-GTGGTGGTGGTGGTG3P) was also used in addition to primers ERIC and REP. Rep fingerprints sharing 


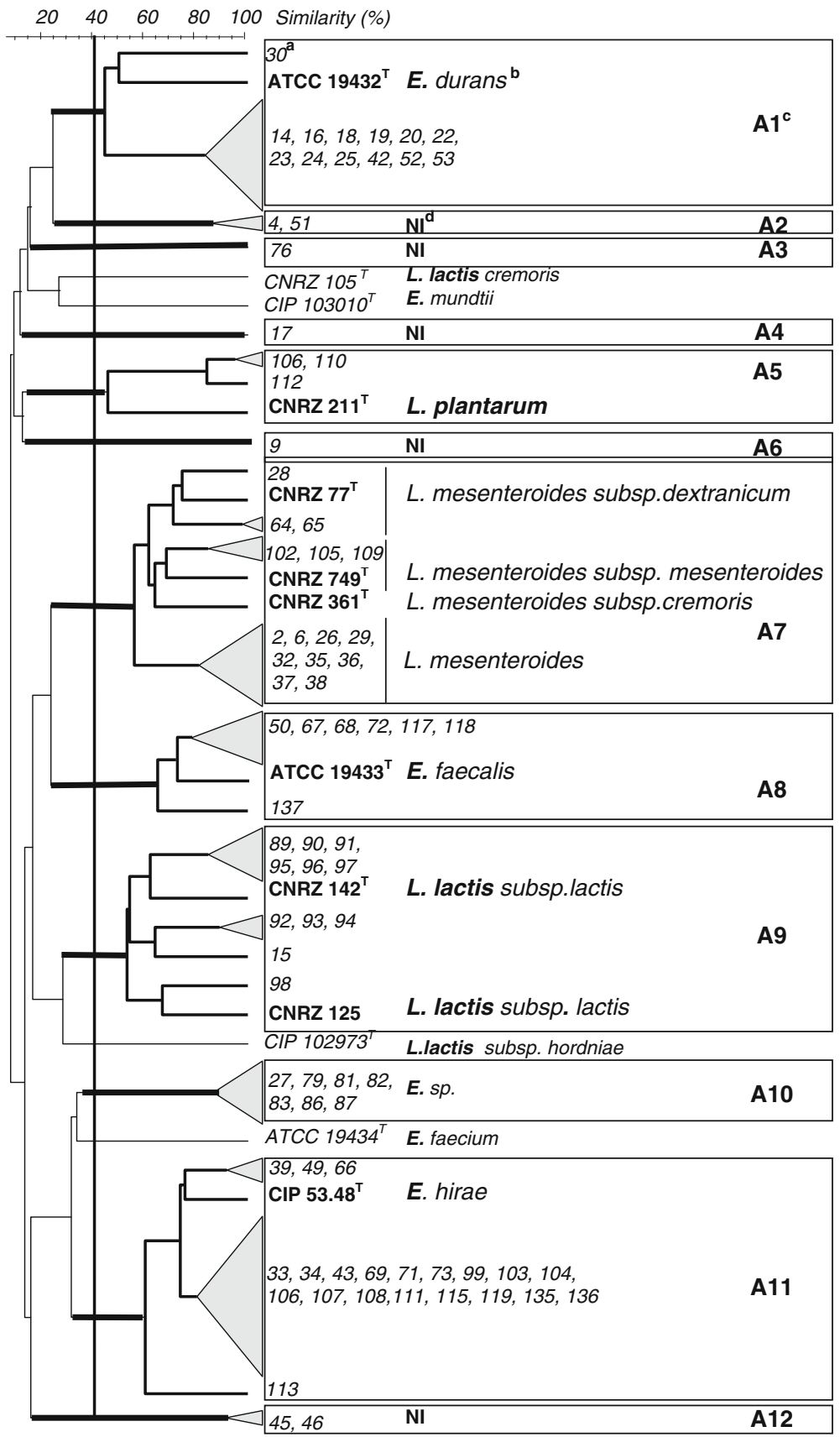

Fig. 1 Dendrogram based on numerical analysis of the 84 concatenated Rep-PCR fingerprints combining ERIC, REP, and (GTG) $)_{5}$ fingerprints. ${ }^{\mathrm{a}}$ Name of isolate or type strain. ${ }^{\mathrm{b}}$ Genotypic affiliation by Rep-PCR, in bold Rep-PCR affiliation confirmed by specific PCR. ${ }^{\mathrm{c}}$ No. of the Rep-PCR group. ${ }^{\mathrm{d}}$ Nonidentified

more than $40 \%$ similarity were grouped together. Rep fingerprints were analyzed as described by Berthier et al. (2001). Briefly, isolates with Rep fingerprints sharing 
more than $40 \%$ similarity with the Rep fingerprint of a type strain were presumptively affiliated to the species that that strain represented. Dissimilar fingerprints were assumed to be fingerprints of different strains. To avoid the erroneous assessment of two dissimilar fingerprints instead of one, similarity between fingerprints was deduced from both clustering analysis and visual inspection. Fingerprints were assumed to be similar when they had the same bands with the same relative intensity. Dissimilar Rep fingerprints within each Rep group were called fingerprint 1, fingerprint $2, \ldots$, fingerprint $x$, revealing genotype 1 , genotype $2, \ldots$ genotype $x$.

\subsection{Specific PCR}

Specific PCR was applied to isolates representative of each Rep-PCR group. The primers used, the microorganisms targeted, the negative and positive controls, and the corresponding references are shown in Table 1.

\subsection{Phenotypic characterization}

\subsubsection{Identification purpose}

The ability of lactococci to produce acid from lactose, glucose, or maltose was assessed in M17-lactose, glucose, or maltose $\left(10\right.$ g. $\left.\mathrm{L}^{-1}\right)$ broth incubated at $30{ }^{\circ} \mathrm{C}$ for $24 \mathrm{~h}$ in the presence of bromocresol purple $\left(0.04 \mathrm{~g} . \mathrm{L}^{-1}\right)$. The ability of lactococci to grow in the presence of $4 \%$ and $6.5 \% \mathrm{NaCl}$ (gram per kilogram) was tested in $\mathrm{M} 17$ broth incubated at $30^{\circ} \mathrm{C}$ for $48 \mathrm{~h}$. The ability of lactococci to grow at $10^{\circ} \mathrm{C}$ and $40{ }^{\circ} \mathrm{C}$ was tested with M17 plates incubated for 10 days and $48 \mathrm{~h}$, respectively. Argininepositive(negative) lactococci were distinguished by their white (yellow) colonies after growth on M16BCP medium (Thomas 1973) at $30{ }^{\circ} \mathrm{C}$ for $24 \mathrm{~h}$.

\subsubsection{Technological purpose}

The ability of lactococci and leuconostocs to acidify at $25^{\circ} \mathrm{C}, 30^{\circ} \mathrm{C}, 37^{\circ} \mathrm{C}, 42^{\circ} \mathrm{C}$, and $50{ }^{\circ} \mathrm{C}$ was tested in $10 \mathrm{~mL}$ sterile reconstituted skimmed milk inoculated with $10^{6}$ to $10^{7} \mathrm{cfu} . \mathrm{mL}^{-1} \cdot \mathrm{pH}$ was recorded after $48 \mathrm{~h}$, i.e., at the end of acidification. The experiment was performed in triplicate, and the three recorded $\mathrm{pH}$ values were averaged (the standard deviations ranged from $0.01 \mathrm{U}$ to $0.04 \mathrm{U}$ ). Protease-positive lactococci were distinguished by the transparent halo around their colonies after growth at $30{ }^{\circ} \mathrm{C}$ on milk agar. Citrate-positive (negative) isolates were distinguished by the blue (white) color of KMK liquid medium (Kempler and McKay 1980) after their growth at $30^{\circ} \mathrm{C}$ for $48 \mathrm{~h}$. Protease and citrate experiments were performed in triplicate.

\section{Results}

\subsection{Isolation of strains}

Eighty-four Gram-positive and catalase-negative isolates, including 81 cocci, were collected from 79 samples representing 40 farms (Table 2). Of the 84 strains isolated, 


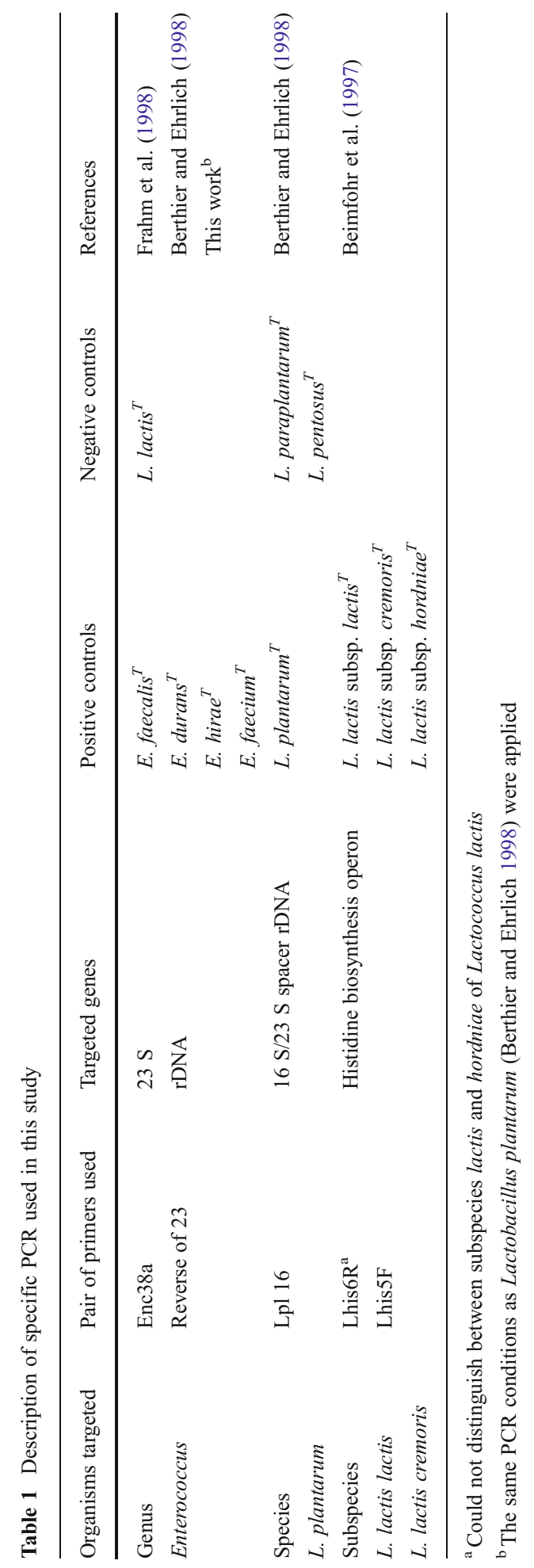

NRA פ̂ Springex 
$38 \%$ were obtained from raw cow's, ewe's, and goat's milks, and $62 \%$ from laboratory-fermented ewe's, goat's, mare's, and camel's milks. Among the cocci, $62 \%$ were isolated on MRS-vancomycin plates and 38\% on M17 plates. From two to 16 isolates (average of nine) were available per medium for each source. The enterococci isolates were collected from both MRS and M17 plates, while the lactococci isolates were collected only from M17 plates and the leuconostocs isolates only from MRS plates, which is usual (Mathot et al. 1994). Enterococci that were isolated on MRS-vancomycin plates originated from fermented milks.

\subsection{Genotypic characterization}

Table 2 summarizes the different genera, (sub)species and genotypes identified among the isolated cocci, according to raw and fermented milks analyzed.

\subsection{1 (Sub)species assignation of isolates}

Seventy-three percent of the isolates (61 out of 84) were assigned with confidence to seven established mesophilic LAB species or subspecies from four genera, i.e., Enterococcus species (41 isolates; E. hirae (21), E. durans (13), E. faecalis (7)), Leuconostoc subspecies (six isolates, L. mesenteroides subsp. mesenteroides (3), L. mesenteroides subsp. dextranicum (3)), Lactococcus subspecies (11 isolates, L. lactis subsp. lactis), and Lactobacillus species (three isolates, L. plantarum). Nineteen additional isolates were assigned with confidence to Enterococcus sp. or L. mesenteroides.

Eighty-one isolates formed nine groups (A1, A2, A5, and A7-A12) and three isolates $(9,17$, and 76$)$ were alone (A3, A4, and A6, respectively), according to the clustering of their Rep-PCR fingerprints at 40\% similarity or higher (Fig. 1). Seventy isolates shared more than $40 \%$ similarity with fingerprints for six established LAB (sub)species, L. mesenteroides, E. hirae, E. durans, E. faecalis, L. lactis subsp. lactis, and $L$. plantarum. The ten isolates of group A10 were related to E. faecium and $E$. hirae, but their fingerprints were less than $40 \%$ homologous with the fingerprints of either E. faecium or E. hirae. The Enterococcus, L. plantarum, and L. lactis subsp. lactis assignations were confirmed by genus- and (sub)species-specific PCR on 13 isolates representing groups A1 (isolate nos. 2 and 30), A5 (isolate no. 106), and A8-A11 (isolates no. 15, 27, 33, 39, 50, 89, 92, 98, 113, and 137). In so doing, the closely related L. paraplantarum, L. pentosus, and L. lactis subsp. cremoris (sub)species were definitively excluded. Six L. mesenteroides isolates of group A7 had subsp. dextranicum or subsp. mesenteroides-type strainlike fingerprints (Fig. 2; fingerprints 1-3). The other nine had a distinct Rep-fingerprint (Fig. 2; fingerprint 4), which presented less similarity to the subspecies-type Rep fingerprints than Rep fingerprints 1-3 of Leuconostoc isolates and could not be related to any of the subspecies-type Rep fingerprints. L. mesenteroides cremoris-type strain (Fig. 2) had a unique Rep fingerprint. Rep group A9 contained L. lactis subsp. lactis genotypes (from 11 isolates and the type strain) but not the L. lactis subsp. cremoristype genotype, as the L. lactis subsp. lactis-type strainlike group A obtained from Multilocus Sequence Analysis and (GTG) $)_{5}$-PCR fingerprinting (Rademaker et al. 2007). 


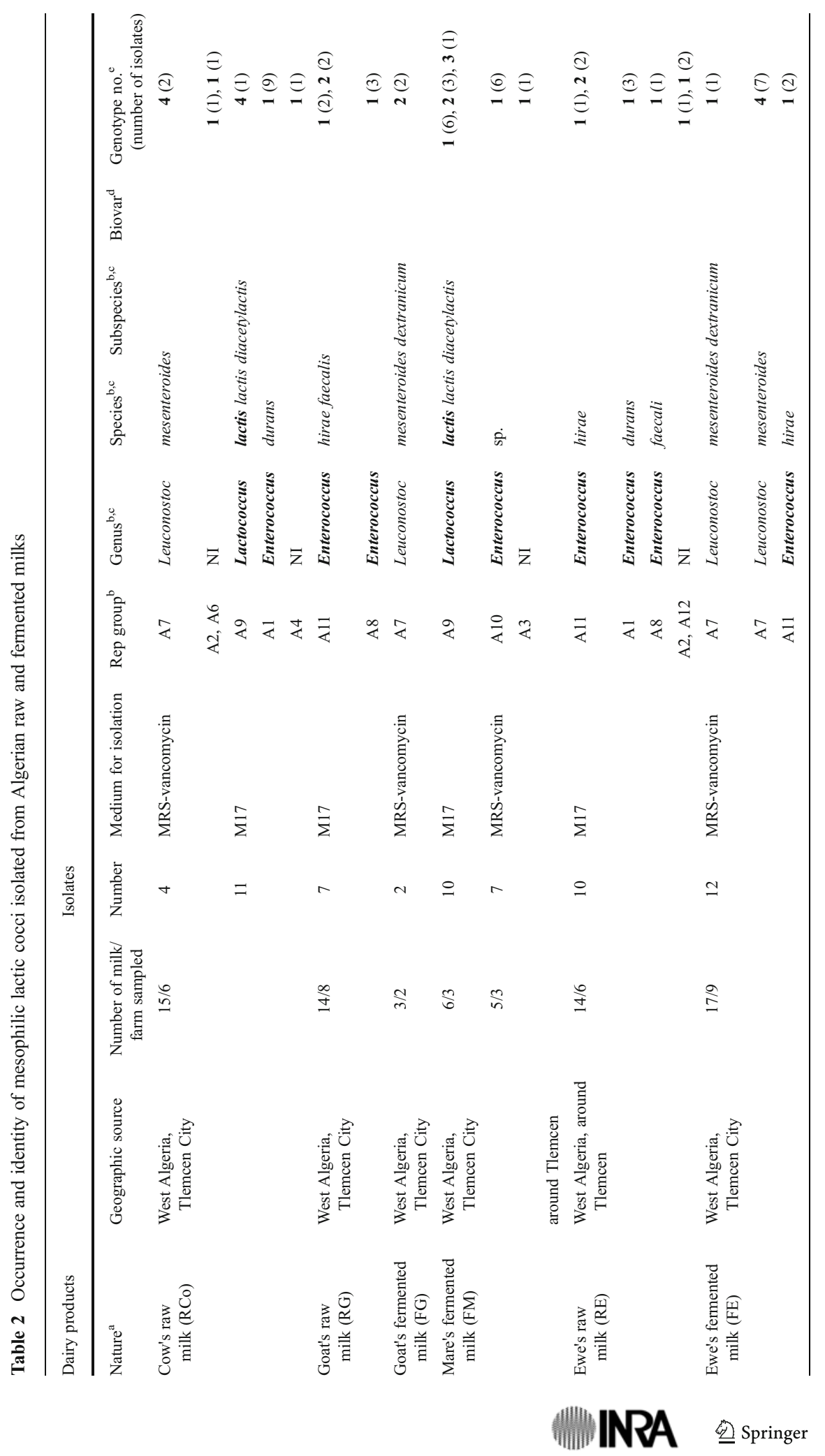




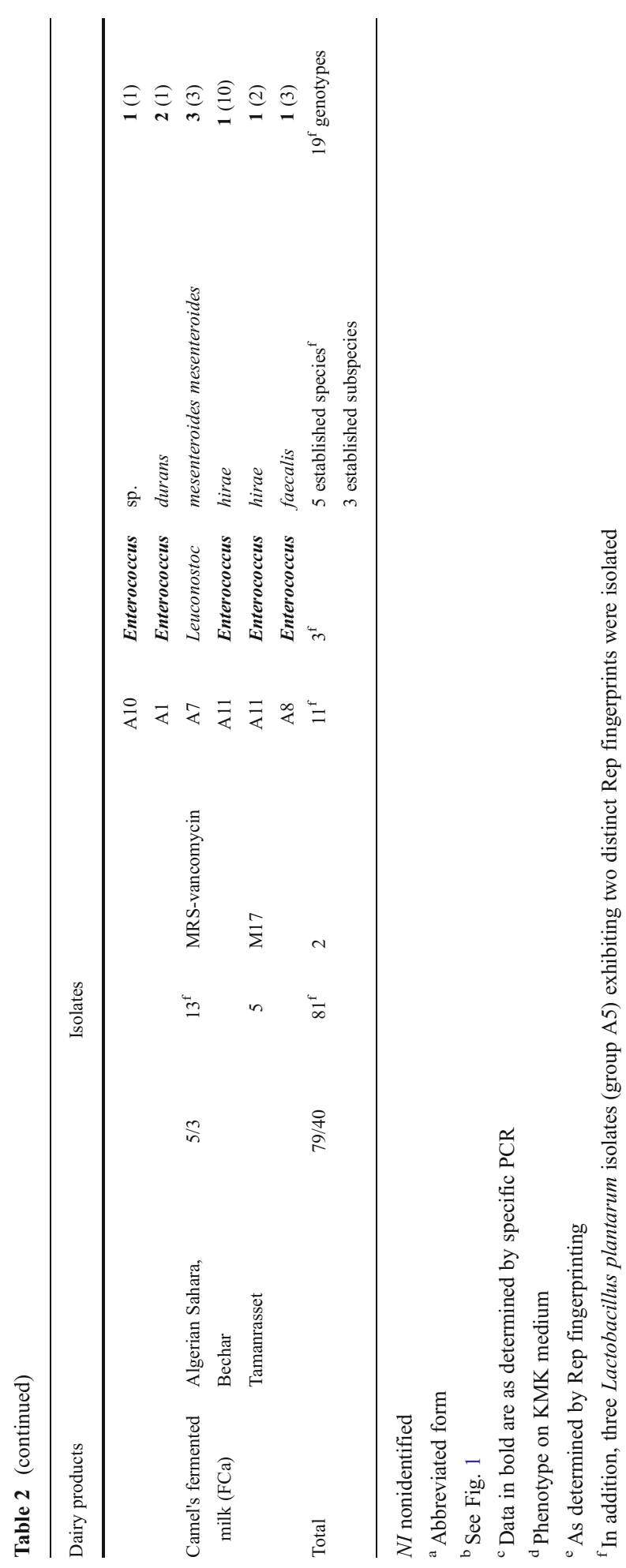




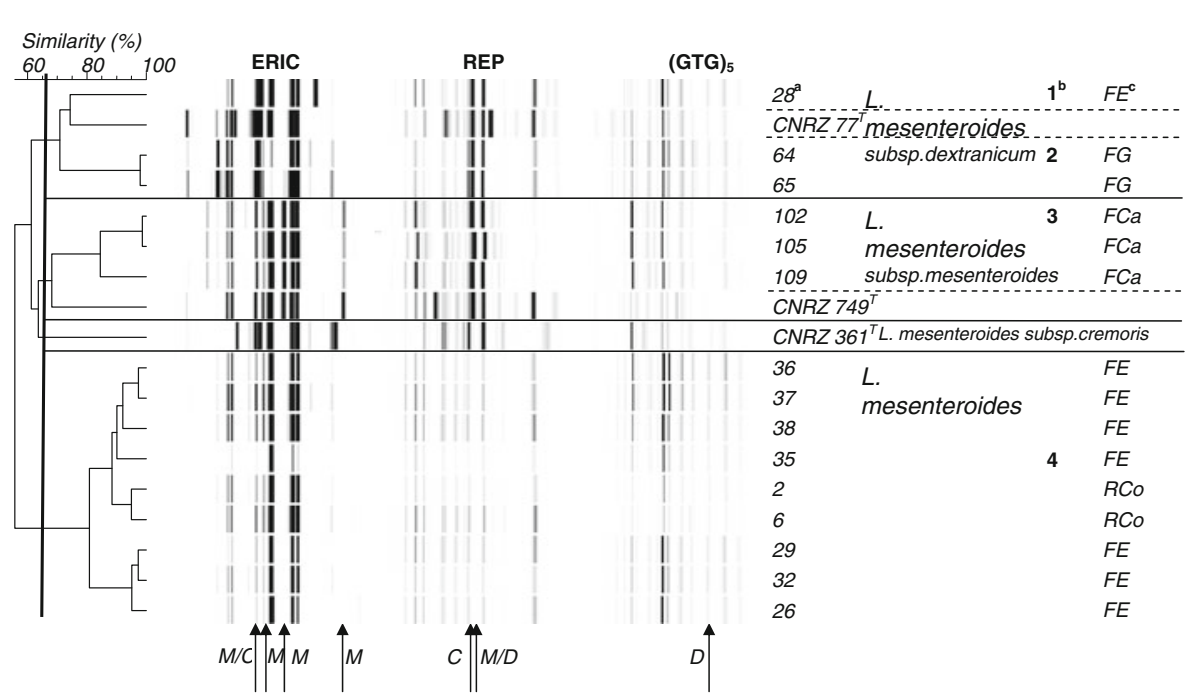

Fig. 2 Dendrogram and Rep fingerprints of Leuconostoc. Rep-group=group A7. Clustering was made with concatenated Rep-fingerprints combining ERIC, REP, and (GTG) 5 fingerprints. Solid horizontal lines separate Leuconostoc subspecies. Dotted horizontal lines separate dissimilar fingerprints within Leuconostoc subspecies. ${ }^{\mathrm{a}} \mathrm{Name}$ of isolate or type strain. ${ }^{\mathrm{b}}$ Genotypic affiliation by Rep-PCR. ${ }^{\mathrm{c}}$ See Table 2 for the meaning of RCo, RG, RS, FCa, FE, FG, and FM. Arrows indicate specific bands of Leuconostoc mesenteroides subsp. cremoris $(C)$, Leuconostoc mesenteroides subsp. dextranicum (D), and Leuconostoc mesenteroides subsp. mesenteroides $(M)$ fingerprints

The five groups A2-A4, A6, and A12 (seven isolates) had fingerprints with less than $40 \%$ similarity with the type fingerprints shown in Fig. 1. Their DNA responded negatively to the Enterococcus-specific PCR. Their fingerprints did not cluster (data not shown) with those of cocci, such as L. garviae, Streptococcus thermophilus, and S. gallolyticus, which are starters for some dairy products. They were not further identified because they were rarely isolated and because they were not affiliated to any of the LAB species previously cited as potential starters.

\subsubsection{Genotypic diversity within (sub)species}

Twenty-one different Rep-PCR fingerprints were distinguished from the 84 isolates according to their clustering. One fingerprint was observed in each of the seven groups A2-A4, A6, A8, A10, and A12; two different fingerprints in each of the three groups A1, A5, and A11 (E. durans, L. plantarum, and E. hirae); and four different fingerprints in groups A9 (L. lactis subsp. lactis) and A7 (L. mesenteroides, Fig. 2), with one in subspecies mesenteroides and two in subspecies dextranicum.

\subsection{Phenotype of the isolates}

Besides common phenotypic traits, the L. lactis and Leuconostoc isolates exhibited phenotypic diversity in spite of the small number of isolates analyzed (ten and 15 isolates, respectively). Some phenotypes were atypical. All L. lactis isolates grew in the presence of $4.0 \% \mathrm{NaCl}$ but not $6.5 \% \mathrm{NaCl}$ and from $10{ }^{\circ} \mathrm{C}$ to $40{ }^{\circ} \mathrm{C}$ and were 


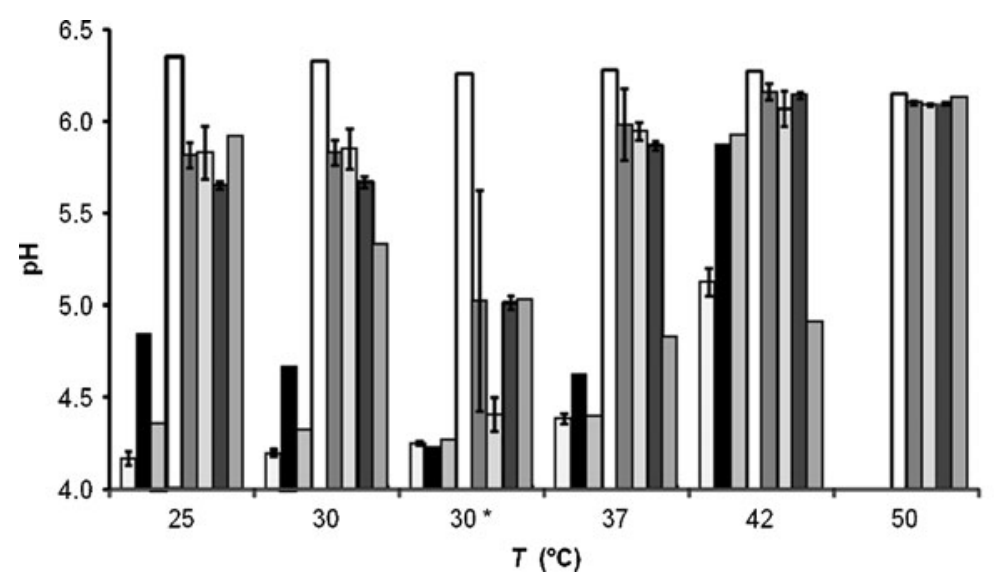

Fig. 3 Acidification potential of the lactococci and leuconostocs isolates in milk. Sterile reconstituted milks were incubated for $48 \mathrm{~h}$ at five different temperatures after inoculation either with one out of the isolates or with one type strain. $30^{*}$ milk incubated at $30^{\circ} \mathrm{C}$ and supplemented with yeast extract $(0.1 \%)$. Isolates and type strains affiliated to the same (sub)species and having similar $\mathrm{pH}$ values were grouped. Individual $\mathrm{pH}$ when isolates or type strains were not grouped $(N=1$, standard deviations ranged between $0.01 \mathrm{U}$ and $0.04 \mathrm{U})$, or mean $\mathrm{pH}$ and standard deviation of groups $(N>1)$, for Lactococcus lactis subsp. lactis with genotypes 1 or 2 ( $N=9$; nine isolates) (light gray); Lactococcus lactis subsp. lactis with genotype 3 ( $N=1$; one isolate) (black); Lactococcus lactis subsp. lactis type strain $\left(N=1\right.$; CNRZ $\left.142^{\mathrm{T}}\right)($ gray $)$; noninoculated milk $(N=1)$ (white); Leuconostoc mesenteroides subsp. dextranicum $(N=4$; three isolates with Leuconostoc genotypes 1 or 2 and CNRZ $77^{\mathrm{T}}$ ) (gray); Leuconostoc mesenteroides subsp. mesenteroides $(N=4$, three isolates with Leuconostoc genotype 3, and CNRZ 749 ${ }^{\mathrm{T}}$ ) (light gray); Leuconostoc mesenteroides $(N=9$; nine isolates with Leuconostoc genotype 4) (dark gray); Leuconostoc mesenteroides subsp. cremoris ( $N=1$; CNRZ $361^{\mathrm{T}}$ ) (gray)

protease-, maltose-, galactose-, lactose- arginine-, and citrate-positive, which is typical of the L. lactis subsp. lactis biovar diacetylactis phenotype. Isolate no. 98 (genotype L. lactis 3) needed a supplementation of milk with yeast extract to acidify to the same extent than the isolates having genotypes 1 and 2 (Fig. 3). The latter isolates were excellent acidifiers from $25^{\circ} \mathrm{C}$ to $37^{\circ} \mathrm{C}$, and still good acidifiers at $42{ }^{\circ} \mathrm{C}$ which is an atypical L. lactis subsp. lactis phenotype (Fig. 3). In the temperature range of $25^{\circ} \mathrm{C}$ to $37^{\circ} \mathrm{C}$, cow's milk was less acidified by leuconostocs isolates than by lactococci isolates, which is usual (Fig. 3). All Leuconostoc isolates produced dextran. Absence of dextran production and the lowest $\mathrm{pH}$ distinguished the type strain of L. mesenteroides subsp. cremoris. Contrary to the Leuconostoc isolates and type strains of subspecies mesenteroides and dextranicum, the type strain of $L$. mesenteroides subsp. cremoris showed improving acidification of the milk as the temperature was increased from $25^{\circ} \mathrm{C}$ to $37^{\circ} \mathrm{C}$, and still at $42{ }^{\circ} \mathrm{C}$ (Fig. 3). However, the type strain had an optimal temperature range of 25 to $30{ }^{\circ} \mathrm{C}$ for acidification when incubated in broth as previously described (Cooper and Collins 1978).

KMK liquid medium indicated citrate use for all isolates that coagulated it, i.e., all E. faecalis and all L. lactis. KMK medium was not coagulated by leuconostocs and other enterococci and indicated a weak citrate use (green color) for L. mesenteroides subsp. cremoris type strain and other Enterococcus isolates. 


\section{Discussion}

In this study, wild strains of leuconostocs (four different strains) and lactococci (four different strains) were isolated from Algerian raw and fermented milks and reliably characterized. Two strains of L. lactis subsp. lactis and one strain of L. mesenteroides subsp. mesenteroides are possible primary starters for the traditional production of Raib and its by-products. They were isolated from camel's and mare's fermented milks, respectively. Enterococci were also unintentionally isolated. The isolates were genotyped, and most strains were reliably identified at the (sub)species level.

The major groups of mesophilic lactic cocci isolated in this study from milks spontaneously fermented in the laboratory are similar to those previously isolated on similar media from their traditionally fermented counterparts (Benkerroum and Tamime 2004). E. hirae was the main Enterococcus species, which is unusual for dairy products (Foulquie Moreno et al. 2006). Isolates assigned to Enterococcus sp. may belong to species Enterococcus lactis, as these isolates were genotypically related to E. faecium. This species, recently proposed for enterococci isolated from different dairy products (Bauer et al. 2009; Morandi et al. 2011a; Sukhodolets et al. 2005), has been recently validated (Morandi et al. 2011b).

Phenotypic plus genotypic methods distinguished four different strains among 15 Leuconostoc isolates. Four genotypes were obtained, genotype 4 having unique phenotypic traits. They were all L. mesenteroides, unlike those predominating in Moroccan Lben, which are Leuconostoc pseudomesenteroides (Ouadghiri et al. 2009). Three genotypes were related to the genotype of the type strains of subspecies mesenteroides or dextranicum. Isolates having these genotypes exhibited the same phenotypic traits as their related subspecies-type strain. The fourth genotype (no. 4), which was shared by nine isolates that produced dextran, clustered with the other $L$. mesenteroides genotypes by Rep-PCR fingerprinting and combined bands characteristic of each Leuconostoc subspecies-type fingerprints. The subspecies mesenteroides strain isolated from camel's fermented milk could be a useful starter when milk has high levels of nutrients, i.e., ewe's and camel's milks (Abu-Tarboush 1994; Park et al. 2007), as shown by its enhanced acidification of milk in the presence of yeast extract. Lower $\mathrm{pH}$ in the presence of yeast extract in milk, especially for the isolates of $L$. mesenteroides subsp. mesenteroides, was in accordance with the lower requirements of this subspecies for growth (Garvie 1986). L. mesenteroides subsp. cremoris is the unique leuconostoc adjunct available in commercial starters. The cremoris-type strain did not produce dextran from sucrose, and was also distinguished by its ability to acidify nonsupplemented cow's milk to (a) lower $\mathrm{pH}$ at temperatures from $25^{\circ} \mathrm{C}$ to $42{ }^{\circ} \mathrm{C}$ and (b) improved acidification as the temperature increased. These last two traits have not yet been described for the subspecies cremoris. Atypical metabolic features and ribotype profile, but typical SDS-PAGE profile, have previously been described for the cremoris-type strain (Cooper and Collins 1978; Villani et al. 1997). Thermotolerance to $50{ }^{\circ} \mathrm{C}$ was recently observed for wild strains of dairy lactococci (Drici et al. 2010) although leuconostocs and lactococci are usually mesophilic bacteria. It would be interesting to explore the link between growth/acidification, thermotolerance, and dextran production observed in this study for leuconostocs. The failure in isolating L. mesenteroides subsp. cremoris strains from raw and fermented 
milks in this study has already been noticed for raw milk cheeses (Hemme and Foucaud-Scheunemann 2004). Such strains could prove to be useful starters when $\mathrm{LAB}$ growth in milk is poor or when the fermentation temperature is above the usual optimal temperature for leuconostocs, $27^{\circ} \mathrm{C}$ (Cooper and Collins 1978), as can be the case during the manufacture of Raib. The strains of leuconostocs isolated in this study were probably capable of metabolizing citrate, as is the case for all leuconostocs described so far (Hemme and Foucaud-Scheunemann 2004); they were recorded as citrate-negative on KMK medium because they grew very poorly on it.

Phenotypic plus genotypic methods distinguished four different strains among 11 lactoccocci isolates. Two of them expressed high acidifying capabilities over a large temperature range of $25^{\circ} \mathrm{C}$ to $42^{\circ} \mathrm{C}$. The latter two strains isolated from mare's fermented milks could be useful starters because of their specific phenotype which may be due to the nondairy niche before contaminating milk. They may also exhibit, contrary to lactococci commonly used as dairy starter, fewer amino acid auxotrophies and various additional capabilities such as additional flavor-forming activities and greater stress tolerance (Ayad et al. 1999; Nomura et al. 2006; Smit et al. 2004). These capabilities may be beneficial to milk fermentation and will be interesting to explore. All lactococci isolates exhibited a protease activity, L. lactis subsp. lactis-like genotypes, and usual L. lactis subsp. lactis biovar diacetylactis phenotype. This subspecies is commonly isolated from Raib by-products (Benkerroum and Tamime 2004).

\section{Conclusion}

Among the eight wild strains of lactococci and leuconostocs collected in this study, two protease-positive L. lactis subsp. lactis biovar diacetylactis strains, L. lactis 1 and 2, and the L. mesenteroides subsp. mesenteroides strain had high acidifying potential in milk. They were isolated from mare's and camel's fermented milks, respectively. These strains can now be tested in the manufacture of Raib. It would be interesting to investigate whether thermophilic homofermentative LAB also play a part in the spontaneous fermentation for Raib. Efficient strain typing is essential for reliable identification of particular strains and tracking of starter cultures, and this study shows that Rep-PCR combining three independent fingerprints is a reliable and discriminating method for leuconostocs, enterococci, and lactococci strains.

Acknowledgments The authors thank Romain Palme for his technical assistance and Harriet Coleman for revising the English.

\section{References}

Abou-Donia S (2008) Origin, history and manufacturing process of Egyptian dairy products. Alex J Food Sci Technol 5:51-62

Abu-Tarboush HM (1994) Growth-behavior of Lactobacillus acidophilus and biochemical characteristics and acceptability of acidophilus milk made from camel milk. Milchwissenschaft 49:379-382

Ayad EHE, Verheul A, deJong C, Wouters JTM, Smit G (1999) Flavour forming abilities and amino acid requirements of Lactococcus lactis strains isolated from artisanal and non-dairy origin. Int Dairy $\mathrm{J}$ 9:725-735 
Bauer R, Bekker JP, Nv W, du Toit C, Dicks LMT, Kossmann J (2009) Exopolysaccharide production by lactose-hydrolyzing bacteria isolated from traditionally fermented milk. Int J Food Microbiol 131:260-264

Beimfohr C, Ludwig W, Schleifer KH (1997) Rapid genotypic differentiation of Lactococcus lactis subspecies and biovar. Syst Appl Microbiol 20:216-221

Bencharif A (2001) Stratégies des acteurs de la filière lait en Algérie: états des lieux et problématiques. Options Méditerranéennes Série B Etudes et Recherches 32:25-45

Benkerroum N, Tamime AY (2004) Technology transfer of some Moroccan traditional dairy products (lben, jben and smen) to small industrial scale. Food Microbiol 21:399-413

Berthier F, Ehrlich SD (1998) Rapid species identification within two groups of closely related lactobacilli using PCR primers that target the 16 S/23S rRNA spacer region. FEMS Microbiol Lett 161:97-106

Berthier F, Beuvier E, Dasen A, Grappin R (2001) Origin and diversity of mesophilic lactobacilli in Comté cheese, as revealed by PCR with repetitive and species-specific primers. Int Dairy J 11:293-305

Chammas GI, Saliba R, Corrieu G, Beal C (2006) Characterisation of lactic acid bacteria isolated from fermented milk "laban". Int J Food Microbiol 110:52-61

Cooper RK, Collins EB (1978) Influences of temperature on growth of Leuconostoc cremoris. J Dairy Sci 61:1085-1088

Drici H, Gilbert C, Kihal M, Atlan D (2010) Atypical citrate-fermenting Lactococcus lactis strains isolated from dromedary's milk. J Appl Microbiol 108:647-657

Foulquie Moreno MR, Sarantinopoulos P, Tsakalidou E, De Vuyst L (2006) The role and application of enterococci in food and health. Int J Food Microbiol 106:1-24

Frahm E, Heiber I, Hoffmann S, Koob C, Meier H, Ludwig W, Amann R, Schleifer KH, Obst U (1998) Application of $23 \mathrm{~S}$ rDNA-targeted oligonucleotide probes specific for enterococci to water hygiene control. Syst Appl Microbiol 21:450-453

Garvie E (1986). Genus Leuconostoc. In: Sneath P, Mair J, Sharpe M, Holt J, (eds) Bergey's manual on systematic bacteriology, Baltimore

Gaya P, Babin M, Medina M, Nunez M (1999) Diversity among lactococci isolated from ewes' raw milk and cheese. J Appl Microbiol 87:849-855

Gevers D, Huys G, Swings J (2001) Applicability of rep-PCR fingerprinting for identification of Lactobacillus species. FEMS Microbiol Lett 205:31-36

Guizani N, Kasapis S, Al Ruzeiki M (2001) Microbial, chemical and rheological properties of laban (cultured milk). Int J Food Sci Technol 36:199-205

Hemme D, Foucaud-Scheunemann C (2004) Leuconostoc, characteristics, use in dairy technology and prospects in functional foods. Int Dairy J 14:467-494

Kempler GM, McKay LL (1980) Improved medium for detection of citrate-fermenting Streptococcus lactis subsp. diacetylactis. Appl Environ Microbiol 39:926-927

Khaldi R, Haddad M, Padilla M (2006) Attentes et attitudes des consommateurs urbains face aux produits laitiers: cas de la commune de Tunis. Options Méditerranéennes Série A Séminaires Méditerranéens 78:365-375

Koussou M, Duteurtre G, Mopota L (2007) Consommation de lait dans les bars laitiers de la ville de N'Djamena au Tchad. Rev Elev Med Vet Pays Trop 60:39-44

Mathot AG, Kihal M, Prevost H, Divies C (1994) Selective enumeration of Leuconostoc on vancomycin agar media. Int Dairy J 4:459-469

Morandi S, Brasca M, Lodi R (2011a) Technological, phenotypic and genotypic characterisation of wild lactic acid bacteria involved in the production of Bitto PDO Italian cheese. Dairy Sci Technol 91:341-359

Morandi S, Cremonesi P, Povolo M, Brasca M (2011b) Enterococcus lactis sp. nov. from Italian raw milk cheeses. Int J Syst Evol Microbiol. doi:10.1099/ijs.0.030825-0

Nomura M, Kobayashi M, Narita T, Kimoto-Nira H, Kamoto T (2006) Phenotypic and molecular characterization of Lactococcus lactis from milk and plants. J Appl Microbiol 101:396-405

Ouadghiri M, Vancanneyt M, Vandamme P, Naser S, Gevers D, Lefebvre K, Swings J, Amar M (2009) Identification of lactic acid bacteria in Moroccan raw milk and traditionally fermented skimmed milk 'lben'. J Appl Microbiol 106:486-495

Park YW, Juarez M, Ramos M , Haenlein GFW (2007) Physico-chemical characteristics of goat and sheep milk. Small Ruminant Res 68:88-113

Prashant TSK, Singh R, Gupta SC, Arora DK, Joshi BK, Kumar D (2009) Phenotypic and genotypic characterization of lactobacilli from churpi cheese. Dairy Sci Technol 89:531-540

Rademaker JLW, Herbet H, Starrenburg MJC, Naser SM, Gevers D, Kelly WJ, Hugenholtz J, Swings J, van Hylckama Vlieg JET (2007) Diversity analysis of dairy and nondairy Lactococcus lactis isolates, using a novel multilocus sequence analysis scheme and (GTG)5-PCR fingerprinting. Appl Environ Microbiol 73:7128-7137 
Samet-Bali O, Bellila A, Ayadi MA, Marzouk B, Attia H (2010) A comparison of the physicochemical, microbiological and aromatic composition of traditional and industrial leben in Tunisia. Int J Dairy Technol 63:98-104

Smit BA, Engels WJM, Bruinsma J, Vlieg JETV, Wouters JTM, Smit G (2004) Development of a high throughput screening method to test flavour-forming capabilities of anaerobic micro-organisms. J Appl Microbiol 97:306-313

Sukhodolets V, Botina S, Lysenko A, Trenina M (2005) The lactic acid enterococci Enterococcus faecium and Enterococcus durans: nucleotide sequence diversity in 16 S rRNA genes. Microbiology 74:704-708

Tantaoui-Elaraki A, El Marrakchi A (1987) Study of Moroccan dairy products: lben and smen. J Appl Microbiol Biotechnol 3:211-220

Terzaghi BE, Sandine WE (1975) Improved medium for lactic streptococci and their bacteriophages. Appl Microbiol 29:807-813

Thomas T (1973) Agar medium for differentiation of Streptococcus cremoris from other bacteria. NZ J Dairy Sci Tech 8:70-71

Vedamuthu ER (1994) The dairy Leuconostoc - use in dairy products. J Dairy Sci 77:2725-2737

Villani F, Moschetti G, Blaiotta G, Coppola S (1997) Characterization of strains of Leuconostoc mesenteroides by analysis of soluble whole-cell protein pattern, DNA fingerprinting and restriction of ribosomal DNA. J Appl Microbiol 82:578-588

Wolfgang L (2007) Nucleic acid techniques in bacterial systematics and identification. Int J Food Microbiol 120:225-236 